\title{
SEXISMO NA ACADEMIA BRASILEIRA: ESTUDO DE CASOS DESDE O SUL DO BRASIL
}

\author{
Gabriela M. Kyrillos ${ }^{1}$ \\ Sheila Stolz ${ }^{2}$
}

\section{RESUMO}

Tendo como ponto fulcral as emblemáticas denúncias de estudantes dos Cursos de Direito de duas Universidades Federais do sul do Brasil: UFSC e FURG, realizar-se-á um breve resgate histórico sobre a inclusão das mulheres no ensino formal e no fazer Ciência, para constatar que, atualmente, persistem os fenômenos conhecidos como "teto de vidro" e "labirinto de cristal" - compreendidos como violência simbólica de gênero - e que, também no ambiente acadêmico-científico, em particular nos cursos de Direito, dita violência precisa ser superada. Conditio sine qua non para uma formação mais plural, diversa e não preconceituosa das(os) futuras(os) profissionais do Direito.

Palavras-Chave: Sexismo; Gênero; Teto de Vidro; Labirinto de Cristal; Ensino do Direito.

\section{SEXISM IN THE BRAZILIAN ACADEMY: STUDY OF CASES FROM THE SOUTH OF BRAZIL}

\begin{abstract}
Taking as its focal point the emblematic denunciations of students of the Law Courses of two Universities of Southern Brazil: UFSC and FURG, there will be a brief historical rescue on the inclusion of women in formal education and in the making of science, to verify that, currently, the phenomena known as "Glass ceiling" and "glass labyrinth" - understood as symbolic gender violence - and that, also in the academic-scientific environment, in particular in the Courses of Law, this violence must be overcome. Conditio sine qua non for a more pluralistic, diverse and unprejudiced formation of the law professionals.
\end{abstract}

Key-words: Sexism; Gender; Glass Ceiling; Glass labyrinth; Legal Education of Law.

\footnotetext{
“As leis são como as mulheres, foram feitas para serem violadas"
}

\footnotetext{
${ }^{1}$ Doutora em Direito pela Universidade Federal de Santa Catarina - UFSC. Mestra em Política Social pela Universidade Católica de Pelotas (UCPel) na linha de Direitos Humanos e Acesso à Justiça. Especialista em Direitos Humanos pelo Centro Universitário Claretiano. Graduada em Direito pela Universidade Federal do Rio Grande (FURG). Atualmente realiza Pós-Doutorado na FURG no Programa de Pós-Graduação em Direito e Justiça Social com bolsa da CAPES e é integrante do Grupo de Pesquisa Direito, Gênero e Identidades Plurais (DGIPLUS/FURG).

${ }^{2}$ Professora Adjunta da Faculdade de Direito e do Programa de Pós-Graduação em Direito e Justiça Social (Mestrado) da Universidade Federal do Rio Grande (FaDir/FURG/RS). Doutora em Direito pela Pontifícia Universidade Católica do Rio Grande do Sul (PUC/RS) e bolsista CAPES. Mestre em Direito pela Universitat Pompeu Fabra (UPF/Barcelona/Espanha). Coordenadora do Grupo de Pesquisa Direito, Gênero e Identidades Plurais (DGIPLUS/FURG) e do Núcleo de Pesquisa e Extensão em Direitos Humanos (NUPEDH/FURG).
} 
(Frase proferida por professor do Curso de Direito da Pontifícia Universidade Católica do Rio Grande do Sul (PUC-RS) em 2015)

\section{INTRODUÇÃO}

O Brasil é um país profundamente desigual ${ }^{3}$. As desigualdades de classe, raça/etnia, gênero, orientação sexual, dentre muitas outras, são parte da nossa história. Nos últimos anos, é inegável a força, dentre outros, dos discursos que expõem as desigualdades e violências baseadas no gênero e com eles ganharam visibilidade as mais diversas barreiras pessoais, profissionais, políticas e afetivas que as mulheres precisam enfrentar cotidianamente. Frases machistas e misóginas - como a que consta no epígrafe - passaram a ser denunciadas por estudantes, ganhando notoriedade a partir da ilimitada divulgação que a internet e as redes sociais proporcionam. A frase aludida, proferida no primeiro semestre de $2015^{4} \mathrm{em}$ sala de aula por um professor da Faculdade de Direito da Pontifícia Universidade Católica do Rio Grande do Sul (PUC/RS, situada em Porto Alegre) não se trata de um fato isolado, atípico e pouco usual, muito antes pelo contrário, pois, em todo país, têm se proliferado os movimentos de denúncia, tais como os que sucederam na região sul do Brasil e que serão retomados ao longo desse artigo.

As pesquisas realizadas ${ }^{5}$ e que originaram o presente texto, têm como objetivo principal refletir sobre a íntima relação existente entre os espaços de educação formal e as desigualdades de gênero desvendando, ademais, as múltiplas e frequentes violências às quais estão expostas as mulheres tanto como estudantes como quanto profissionais quando acessam o último escalão do ensino formal: a graduação e a pós-graduação stricto e latu sensu. Analisar-se-á, portanto, as desigualdades existentes em um cenário de igualdade formal, no qual as mulheres ainda não possuem no plano prático as mesmas condições de ingresso e,

3 No que concerne as desigualdades de gênero, é válido considerar que: "A taxa de desemprego das mulheres é cerca de duas vezes a dos homens, uma diferença que aumenta quando se comparam homens brancos $(5,3 \%)$ com mulheres afrodescendentes $(12,5 \%)$. Apenas um quarto das mulheres empregadas está no setor formal. O salário médio para os homens é 30\% maior do que o de mulheres. Um terço das famílias brasileiras é chefiada por mulheres, e metade delas é monoparental. As mulheres dedicam mais do que o dobro de seu tempo para as tarefas domésticas do que os homens. A taxa de feminicídio para as mulheres dobrou entre 1980 e 2011 , e hoje uma mulher é assassinada a cada duas horas, a maioria por homens com os quais têm relações íntimas, colocando o Brasil como o sétimo país do mundo com maiores taxas de feminicídio. Em 2012, o número de estupros foi superior a 50.000." De acordo com o site da Organização das Nações Unidas dedica à igualdade de gênero. Disponível em: http://www.onumulheres.org.br/brasil/visao-geral. Acesso em 25 de jul. de 2016.

Pode-se encontrar a notícia em diversos sites, inclusive no Jornal gaúcho de maior circulação e abrangência, Zero Hora, no seguinte link: http://zh.clicrbs.com.br/rs/porto-alegre/noticia/2015/04/piada-deprofessor-sobre-leis-e-mulheres-gera-polemica-entre-estudantes-da-pucrs-4746132.html. Acesso em 15 de ago. de 2015.

No âmbito do Projeto de pesquisa Gêneros, Violências e Direitos Humanos.

Revista de Gênero, Sexualidade e Direito| e-ISSN: 2525-9849 | Salvador | v. 4 | n. 1 | p. 43 - 61 | Jan/Jun. 
principalmente, de continuidade na carreira acadêmico-científica. Ponderando-se, ademais, sobre em que consistem e que papel jogam as violências sexistas e misóginas dentro das universidades, sobretudo porquê atingem não apenas as professoras-pesquisadoras, mas também as estudantes (recorde-se que hoje o corpo discente é majoritariamente composto por mulheres $^{6}$ ) e funcionárias - mesmo que sobre estas últimas exista uma imensa lacuna informativa que ainda precisa ser preenchida por pesquisas futuras.

O conceito de violência simbólica de Pierre Bourdieu servirá de suporte para compreender fenômenos conhecidos como "teto de vidro" e "labirinto de cristal", que representam, em síntese, barreiras verticais e horizontais que dificultam o acesso das mulheres aos mais altos cargos e melhores bolsas, bem como, a conseguirem transitar livremente em todas as áreas do conhecimento, independentemente dos papéis de gênero.

Outrossim, pretende-se contribuir para que se construam ambientes educacionais e científicos no qual as mulheres sintam-se tão seguras, respeitadas e valorizadas quanto os homens, daí a importância de analisar, desde os subsídios fornecidos pelas teorias feministas, as denúncias realizadas por estudantes de graduação em todo o país e onde se constata, em definitivo, que elas (e também eles) não suportam mais as agressões que vivenciam. A fim de alcançar tais objetivos, na primeira seção efetuar-se-á um breve resgate histórico sobre a inclusão das mulheres no ensino formal e no fazer Ciência, para averiguar que, atualmente, mesmo sendo partícipes ativas do mundo acadêmico-científico as mulheres seguem enfrentando os fenômenos conhecidos como "teto de vidro" e "labirinto de cristal" compreendidos como violência simbólica de gênero. Fundamentando-se no conceito de gênero, analisar-se-á, na segunda seção, as denúncias levadas a termos pelas(pelos) estudantes dos Cursos de Direito da Universidade Federal de Santa Catarina (UFSC) e da Universidade Federal do Rio Grande (FURG) entendendo-as como atos de fala de um particular sujeito historicamente emudecido: as mulheres. Manifestações que evidenciam a discriminação sexista e misógina a que estão expostas tanto as professoras-pesquisadoras como também as estudantes dos Curso de Direito em todo território nacional para concluir que também no ambiente acadêmico-científico e, em particular, nos cursos de Direito, a violência simbólica

\footnotetext{
6 Segundo o Censo da Educação Superior de 2016 realizado pelo Instituto Nacional de Estudos e Estatísticas Educacionais Anísio Teixeira (Inep), autarquia pública vinculada ao Ministério da Educação (MEC), existiam em 2016 no Brasil 34.366 cursos de graduação ofertados por 2.407 instituições de educação superior (IES). Naquele ano atingiu-se, adamais, um total de 8.052.254 de estudantes matriculados no ensino superior. O curso de Direito está entre os que possui maior número de estudantes matriculados num total de 862.324. O Censo aponta também que $71,7 \%$ das matrículas em cursos de licenciatura são do sexo feminino, enquanto 28,9\% são do sexo masculino. Veja-se mais informações sobre o ensino superior em: Inep (2016).
} 
precisa ser superada como conditio sine qua non de um ambiente educacional e de trabalho livre de preconceitos e estereótipos de gênero como também para uma formação mais plural, diversa e não preconceituosa das(os) futuras(os) profissionais do Direito.

\title{
2. Da Ciência Moderna até o direito a educação: o longo percurso de exclusão das mulheres da vida pública
}

\author{
Com a expressão teto de vidro ${ }^{7}$ se designa todo o \\ conjunto de práticas e manobras que tem como \\ resultado a desvalorização das mulheres. \\ (VALCÁRCEL, 1997, p. 98).
}

Com o intuito de realizar uma reflexão sobre a papel que a Ciência desempenha hoje no Brasil, bem como na maior parte dos países ocidentais, em questões de gênero, faz-se necessário retroceder, ainda que de forma brevíssima, a Modernidade. Muitas são as formas possíveis de compreender o surgimento da Modernidade, nos parágrafos a seguir tratar-se-á de duas formas distintas.

A primeira delas e mais hegemônica, é aquela que apresenta o surgimento deste período histórico como sendo o início da Idade da Razão, da iluminação diante do período de obscurantismo em que a humanidade esteve submersa durante toda a Idade Média e onde os dogmas religiosos e míticos eram as bases da organização social. Uma das principais referências intelectuais deste momento foi René Descartes (1596-1650) ${ }^{8}$ que, em síntese, proclamava a superioridade de tudo que é conhecido e interpretado pela razão, através da conhecida máxima latina cogito ergo sum, impondo, desta forma, a razão sobre os sentidos, considerados meras distrações ${ }^{9}$. Importante relembrar que no discurso hegemônico sobre a

$7 \quad$ Segundo Sheila Stolz, o termo Glass ceiling barriers, foi "empregado por primeira vez nos Estados Unidas da América em um artigo intitulado “Corporate Woman" publicado em 1995 no Wall Street Journal's e no qual se identificava o teto de cristal ou teto de vidro como um intrigante fenômeno que criava barreiras invisíveis a que se viam expostas as mulheres trabalhadoras altamente qualificadas e que lhes impedia de alcançar, independentemente de seus méritos e de suas conquistas, os níveis hierárquicos mais altos no mundo empresarial. A expressão voltou a ser utilizada em 1995 na publicação do relatório da Federal Glass Ceiling Commission intitulado Good for Business: Making Full Use of the Nation's Human Capital (U.S., 1995)" (2015, p.200).

Particularmente depois da publicação, em 1637, da obra, "Discours de la méthode pour bien conduire sa raison, et chercher la verité dans les sciencesque" (Discurso sobre o método para bem conduzir a razão na busca da verdade dentro da ciência).

Desde esta perspectiva, podemos dizer que a Modernidade surge como um ato de auto-salvação semelhante à clássica história do Barão de Münchhausen (Karl Friedrich Hieronymus von Münchhausen (17201797) notório por contar histórias fantásticas de seus feitos e realizações e que deram origem a obra "As Aventuras do Barão de Münchhausen" organizada por Rudolph Erich Raspe em 1785) na qual ao se encontrar afundando em um pântano sobre seu cavalo teve a brilhante ideia que foi capaz de salvar sua vida e a do animal: puxou por seus cabelos e retirou assim, a ambos, da lama pantanosa.

Revista de Gênero, Sexualidade e Direito| e-ISSN: 2525-9849 | Salvador | v. 4 | n. 1 | p. 43 - 61 | Jan/Jun. 
Modernidade, os únicos sujeitos que aparecem - enquanto agentes ativos - são os homens europeus ${ }^{10}$ proprietários de títulos e de bens que construíram, a partir deste locus, um discurso lógico-racional que buscava demonstrar e legitimar sua superioridade tanto localmente sobre as mulheres, independentemente da classe social a que pertenciam, e sobre os “alcunhados sans-culottes (trabalhadores, artesãos, e pequenos proprietários) (STOLZ, 2015, p. 108) - como também em âmbito global pressupondo que a Europa era o topo do mundo e seu saber e cultura um telos universal ${ }^{11}$ - pensamento dominante na Ciência Moderna.

Um segundo modo de compreender o início da Modernidade associa-a ao "descobrimento" 12 das Américas. Desde esta perspectiva, tal qual esclarece Santiago CastroGomez (2005, p. 47-48), não há como separar a Modernidade do colonialismo, por que a Europa somente conseguiu se colocar como "centro" do sistema-mundo quando constitui as colônias como "periferias"13.

Em certa medida, as duas formas de entender a Modernidade podem dialogar ${ }^{14}$. De fato, o caráter científico de iluminação é um elemento muito importante para compreender não apenas o colonialismo, como também a colonialidade ${ }^{15}$. Os novos modos de organização social impostos a partir de então, centrados no papel do Estado-nação e na suposta supremacia europeia, contou com o discurso da Ciência para legitimar-se. Corroborando o pensamento de

10 Este telos universal, conforme o Enrique Dussel (2005, p. 60): "é eurocêntrico, provinciano, regional. A modernidade é [tida como] uma emancipação, uma 'saída' da imaturidade por um esforço da razão como processo crítico, que proporciona à humanidade um novo desenvolvimento do ser humano.".

Como afirmou Dussel: "El mito del origen que está escondido en el 'concepto' emancipatorio de modernidad, y que continua subtendiendo la reflexión filosófica y muchas otras posiciones teóricas en el pensamiento de Europa y Norteamérica, tiene que ver sobre todo con la conexión del eurocentrismo con la concomitante 'falacia de desarrollismo'. La falacia de desarrollismo consiste en pensar que el patrón del moderno desarrollo europeo debe ser seguido unilateralmente por toda otra cultura. Desarrollo tomado aquí como una categoría ontológica y no simplemente sociológica o económica." (DUSSEL, 1988, p. 60)

${ }_{12}$ Sobre este tema, Enrique Dussel (2013, p. 58) afirma acertadamente que a Europa "pudo autoconstituirse como un unificado ego explorando, conquistando, colonizando una alteridad que le devolvía una imagen de sí misma. Este otro, en otras palabras, no fue 'des-cubierto', o admitido, como tal, sino disimulado, o 'en-cubierto'"'.

13 A exploração dos territórios “descobertos”, nessa interpretação, não está associada apenas com a dominação econômica - exercida por meios bélicos - mas, também vinculada a instauração de um domínio subjetivo de subjugação da(do) outra(o) enquanto ser não apenas diferente como também inferior - seja porque as cosmovisões eram diferentes da cristã, seja porque a cultura, o modo de vestir-se e/ou idioma eram diferentes. De fato, a diversidade tornou-se desigualdade na medida em que também as concepções de mundo e de humanidade foram sendo hierarquizadas conforme o padrão/modelo Europeu.

14 É possível reconhecer a relevância histórica da violenta colonização das Américas e, ao mesmo tempo, o papel central da construção de uma base epistemológica da Modernidade a partir do pensamento de Descartes. ${ }_{15}$ Apesar de partir das relações que surgem com o colonialismo, o conceito de conceito vai além dos elementos materiais e inclui elementos subjetivos de dominação, fazendo com que predomine tanto entre colonizadores, quanto entre colonizadas(os), uma mesma escala de valores, na qual tudo que diz respeito à sociedade e a cultura do colonizador é tido como melhor e como um objetivo que deve ser perseguido por todas as pessoas.

Revista de Gênero, Sexualidade e Direito| e-ISSN: 2525-9849 | Salvador | v. 4 | n. 1 | p. 43 - 61 | Jan/Jun. 
Castro-Gomez, Boaventura de Sousa Santos (2009, p. 61) também assevera que a pretensão de universalidade da Ciência Moderna, baseada na racionalidade científica, foi capaz de criar um modelo totalitário apto a negar todo e qualquer caráter racional às demais formas de conhecimento. Modelo, ademais, feito por e para homens que nem mesmo algumas poucas mulheres aristocratas e/ou burguesas com conhecimentos iguais a de seus pares homens foi capaz de romper. Pois, como bem recorda Jacqueline Leta não lhes era permitido às mulheres “o acesso às intensas e calorosas discussões que aconteciam nas sociedades e academias científicas, que se multiplicaram no século XVII por toda a Europa" (LETA, 2003, p. 271). Circunstância que começou a mudar na segunda metade no século XX, quando a necessidade crescente de recursos humanos para atividades estratégicas, como a ciência, aliada a luta pela igualdade de direitos entre homens e mulheres permitiu-lhes "acesso, cada vez maior, à educação científica e à carreiras, tradicionalmente ocupadas por homens" (LETA, 2003, p. 271)

Quando se trata especificamente da história brasileira, não apenas a participação das mulheres na Ciência é recente, como também o é a própria consolidação no país da esfera acadêmico-científica. Como se sabe, a "história brasileira é pautada, durante mais de quatro séculos, pela ocupação e exploração eminentemente rural e monocultora" (STOLZ; GUSMÃO, 2017, p. 304) fundada na expropriação da mão de obra escravizada de modo que pouquíssima atenção foi dada a educação, amplu sensu, e ao ensino formal (BELTRÃO; ALVES, 2009, p. 125). Somente no século XIX surgem as primeiras instituições dedicadas ao ensino formal de mulheres, com enfoque muito específico no que se consideravam as verdadeiras habilidades e características do ser mulher. Cabendo, portanto, às meninas, uma educação primária que seguia o modelo rousseauniano voltado, exclusivamente, para elementos morais e sociais úteis as futuras "sophies"16 brasileiras, mães e esposas dos novos cidadãos desta terra ${ }^{17}$. No que concerne ao âmbito profissional, até os anos de 1930, o magistério era o único trabalho considerado digno para as mulheres ${ }^{18}$, pois podia ser exercido

16 Conforme Sheila Stolz, na "obra "Conversations d'Émilie” (Conversações sobre o Emílio, 1774/1996), a escritora francesa Louise d'Épinay e contemporânea de Rousseau, também faz inúmeras críticas a "Emílio", sobretudo no que concerne ao papel de Sophie" (STOLZ, 2015, p. 121).

17 Como um espaço social, a escola, nas sociedades urbanas ocidentais modernas, era "um locus privilegiado para a formação de meninos e meninas, homens e mulheres" e, como tal, "um espaço generificado, isto é, um espaço atravessado pelas representações de gênero" (LOURO, 1997, p. 77)

18 Neste sentido, Jane Soares de Almeida assevera que [...] primeiramente destinada às jovens de poucos recursos e às órfãs sem dote, às quais era interdito os sonhos de um bom casamento, dado que este apoiava-se necessariamente em bases econômicas. Sendo difícil casar-se, precisavam essas moças, para não ser um peso para a sociedade, conseguir um meio de subsistência proporcionado por uma profissão digna, de acordo com o 
de forma a não prejudicar às tarefas e responsabilidades domésticas e de cuidado. Sem acesso ao ensino secundário - que hoje se denomina ensino médio - as mulheres estiveram totalmente excluídas do ensino superior durante todo o século XIX. Dando continuidade, portanto, ao hiato de gênero (gender gap) não somente no que diz respeito ao acesso ao ensino fundamental, médio e universitário, mas também ao limitado ingresso a qualquer carreira profissional que não considerada relevante aos padrões femininos, desigualdades deliberadamente impostas pelo Estado e a sociedade e que durará até a segunda metade do século $\mathrm{XX}^{19}$.

Somente com o surgimento da Lei 4.024 de 20 de dezembro de 1961, conhecida como Lei de Diretrizes e Bases da Educação (LDB), ficou garantido o acesso igualitário de mulheres e homens ao ensino médio. Ademais, equipararam-se todos os cursos de nível médio, de modo que o magistério passa a ser aceito para o posterior ingresso nos cursos de graduação. Durante a Ditadura Militar (1964-1985), o Governo “inspirou-se” no formato de ensino dos Estados Unidos e, com o intuito de atender as exigências internacionais, houve, por parte do Estado, um significativo investimento na pós-graduação. Com o retorno à democracia, em especial a partir da década de 2000, ocorre um grande crescimento no número de vagas e de cursos de graduação no país ${ }^{20}$, cenário fundamental para eliminar, depois de séculos, o hiato de gênero no acesso ao ensino básico e superior. Portanto, quando se trata do acesso à educação inexiste, desde a segunda metade do século XX, qualquer processo de discriminação formal com base no gênero e o grande aumento no número de mulheres nas salas de aula é um reflexo desta iniciativa jurídico-política.

ideal feminino e que não atentasse contra os costumes herdados dos portugueses de aprisionar a mulher no lar e só valorizá-la como esposa e mãe. Portanto, ser professora representava um prolongamento das funções domésticas e instruir e educar crianças, sob o mascaramento da missão e da vocação inerentes às mulheres, significava uma maneira aceitável de sobrevivência, na qual a conotação negativa com o trabalho remunerado feminino esvaía-se perante a nobreza do magistério. (1996, p. 74)

19 Segundo os professores Kaizô Iwakami Beltrão e José Eustáquio Diniz Alves, as "mulheres foram excluídas dos primeiros cursos de Medicina (1808), Engenharia (1810) e Direito surgidos no país. O decreto imperial que facultou à mulher a matrícula em curso superior data de 1881. Todavia, era difícil vencer a barreira anterior, pois os estudos secundários eram essencialmente masculinos, além de caros e os cursos normais não habilitavam as mulheres para as faculdades. A primeira mulher a obter o título de médica no Brasil foi Rita Lobato Velho Lopes, em 1887. O importante a notar é que, durante o século XIX e a primeira metade do século XX, a exclusão feminina dos cursos secundários inviabilizou a entrada das mulheres nos cursos superiores. Assim, a dualidade e a segmentação de gênero estiveram, desde sempre, presentes na gênese do sistema educacional brasileiro [...].” (2009, p. 128).

20 Para maiores informações sobre este tema recomenda-se o acompanhamento dos levantamentos realizados pelo Instituto Nacional de Estudos e Pesquisas Educacionais, autarquia federal vinculada ao Ministério da Educação (MEC). 
No entanto, como é sabido, ainda que seja relevante a eliminação de barreiras discriminatórias formais, estas não são, necessariamente, a garantia de um acesso igualitário ao ensino e, menos ainda, ao acesso igualitário a postos de trabalho e de ascensão na carreira. E, quando se trata especificamente do acesso ao ensino superior, à pós-graduação e à carreira acadêmica, as barreiras ainda estão marcadamente presentes.

\begin{abstract}
A exclusão das mulheres da ciência foi mapeada de duas formas: a horizontal ou territorial, que trata da divisão de áreas do conhecimento caracterizadas em femininas ou masculinas nas ciências, e a vertical ou hierárquica, que se refere à exclusão das mulheres do topo da carreira científica, fenômeno também chamado "teto de vidro". Na exclusão horizontal, percebe-se o maior número de mulheres em áreas construídas como de menor prestígio. Na exclusão vertical, o "teto de vidro" é utilizado como metáfora ao se referir à invisibilidade das barreiras que dificultam e impedem a ascensão das mulheres na carreira. (LIMA, 2008, p. 08)
\end{abstract}

Deste modo, é possível reconhecer que a exclusão das mulheres no mundo acadêmico, apesar da igualdade formal, não ocorre de modo efetivamente igualitário. Este processo de inclusão/exclusão das mulheres remete ao clássico conceito de violência simbólica cunhado pelo sociólogo francês Pierre Bourdieu e bem retratado nos parágrafos que seguem:

De fato, jamais deixei de me espantar diante do que poderíamos chamar de o paradoxo da doxa: o fato de que a ordem do mundo, tal como está [...] seja grosso modo respeitada, que não haja um maior número de transgressões ou subversões, delitos e "loucuras" [...] ou, o que é ainda mais surpreendente, que a ordem estabelecida, com suas relações de dominação, seus direitos e suas imunidades, seus privilégios e suas injustiças, salvo uns poucos acidentes históricos, perpetue-se apesar de tudo tão facilmente, e que condições de existência das mais intoleráveis possam permanentemente ser vistas como aceitáveis ou até mesmo naturais. Também sempre vi na dominação masculina, e no modo como é imposta e vivenciada, o exemplo por excelência dessa submissão paradoxal, resultante daquilo que eu chamo de violência simbólica, violência suave, que se exerce essencialmente pelas vias puramente simbólicas da comunicação e do conhecimento, ou, mais precisamente, do desconhecimento, do reconhecimento ou, em última instância, do sentimento. (BOURDIEU, 1999, p. 7-8)

A partir desta definição, é possível compreender a existência da violência simbólica em distintos contextos, inclusive no campo acadêmico. A utilização do termo simbólico não significa estar diante de uma violência "meramente espiritual", pois não se trata de analisar o simbólico como oposto do que é real e efetivo, mas sim, de reconhecer a "objetividade da experiência subjetiva das relações de dominação" (BOURDIEU, 1999, p. 46). Esta objetividade dos elementos simbólicos, quando se trata do campo acadêmico-científico, se reflete no menor acesso das mulheres aos mais altos níveis hierárquicos da academia, às melhores bolsas e oportunidades. 
$\mathrm{Na}$ pesquisa realizada por Jacqueline Leta (2003) ela apresenta dados da Universidade Federal do Rio de Janeiro, que são, em alguma medida, indicativos da realidade nacional acerca da difícil ascensão das mulheres no cenário acadêmico; a título exemplificativo destacar-se-ão apenas dois dados: 1) que, apesar do aumento ao longo dos anos no número de bolsistas mulheres em todas as modalidades existentes, quanto mais alto o nível hierárquico da bolsa, menor o número de mulheres, dado que se repete, inclusive, quando se trata das bolsas de produtividade destinadas a professoras e professores; 2) que, quando se aventa sobre o acesso a cargos administrativos, apenas $24 \%$ dos cargos da UFRJ são ocupados por mulheres - mesmo em departamentos onde as mulheres são maioria numérica. Desta forma, é possível identificar como, em pleno século XXI, a atuação de mulheres enquanto docentes e pesquisadoras em cursos de graduação e pós-graduação é ainda um ato de resistência em um ambiente que guarda os resquícios de uma Ciência feita por homens e para homens.

Comumente, a explicação que se utiliza para justificar a ausência de mulheres nos mais altos níveis da hierarquia acadêmica, funda-se na afirmação de que elas não estariam cumprindo os requisitos formais para ascenderem profissionalmente. Mais uma vez, temos aqui a presença da igualdade formal, de modo que, todas e todos que desejam conseguir bolsas ou ascender na hierarquia universitária devem cumprir requisitos específicos e, em especial, de produção acadêmica. Argumenta-se, recorrentemente, que as mulheres não cumprem os requisitos de produtividade, de modo que são lógica e racionalmente preteridas no momento de concessão de bolsas - condicionante que acaba por retrasar e/ou impedir a ascensão na careira acadêmica de professoras-pesquisadoras.

Sobre as inferências lógicas trazidas a colação faz-se necessário contra-arrestar de forma racional. Ponderando, primeiramente, que o argumento fundado em uma suposta meritocracia acadêmica comumente ignora todas as desigualdades estruturais que predominam nas sociedades ocidentais e, em particular, no Brasil e que se reproduzem, fielmente, dentro dos muros das Universidades e Centros de Pesquisa. Como mencionado no início desse texto, a estrutura desigual de gênero ainda mantém viva a divisão sexual do trabalho, ou seja, são as mulheres que todavia dedicam maior tempo às atividades domésticas e de cuidado e, no que concerne ao âmbito público, são elas que recebem salários menores mesmo exercendo as mesmas atividades que os homens; circunstâncias que se agravam quando se tratam de mulheres negras. Tais fatores, além de muitos outros, ainda que constem 
em pesquisas nacionais disponíveis on line e de livre acesso realizadas por Centros de Pesquisa reconhecidos e idôneos como, por exemplo, o Instituto Brasileiro de Geografia e Estatística (IBGE) e o Instituto de Pesquisa Econômica Aplicada (Ipea ${ }^{21}$ ), são totalmente invisibilizados e/ou não levados em consideração pelas agências de fomento à pesquisa, quando se pressupõe, a título de imparcialidade, que todas as pessoas têm o mesmo acesso e as mesmas oportunidades de cumprirem os requisitos de produção impostos pela vida acadêmica.

Em segundo lugar, convém destacar, que a hipótese acerca da suposta produção inferior das mulheres tem se demonstrado falsa, ao menos quando se trata do Brasil. A pressuposição de que as cientistas mulheres produzem menos que os cientistas homens surgiu de uma pesquisa realizada nos Estados Unidos na década de 1960 e, em certa medida, perpetuou-se no discurso universal/universalizante acerca da produção acadêmica. E, ainda que no Brasil as pesquisas sobre o tema, especialmente com compilação de dados, sejam muito escassas, em 1998, Léa Velho e Elena Leon analisaram a produção das cientistas e o acesso aos cargos mais altos da hierarquia acadêmica na UNICAMP. Naquela pesquisa, as autoras averiguaram que em todas as áreas estudadas - com exceção de uma ${ }^{22}$ - as mulheres contribuíram para a produção científica de modo proporcionalmente equivalente à contribuição masculina (1998, p. 335). Em outros termos, a pesquisa realizada pelas autoras, demonstrou que as cientistas não apenas produzem em números proporcionalmente equivalentes ao produzido pelos homens, mas que também têm equivalência quanto aos veículos de publicação, tendo em áreas como a Física e a Química onde tradicionalmente se publicam nos veículos tidos como mais relevantes para a Ciência, maior produção proporcional de publicações que os homens (VELHO; LEON, 1998, p. 336).

21 Veja-se, por exemplo, a pesquisa realizado por Luana Simões Pinheiro, Antonio Teixeira Lima Junior, Natália de Oliveira Fontoura e Rosane da Silva e intitulada "Mulheres e Trabalho: breve análise do período 2004- 2014" de 2016.

22 O curso com produção de mulheres proporcionalmente menor que de homens foi o de Ciências Sociais. Sobre esta particularidade, é interessante destacar que também "na Biologia, ainda que em menor extensão que nas Ciências Sociais, existe uma defasagem entre participação no corpo docente e contribuição à produção científica. Parece que se estabelece, assim, um padrão em que nas áreas em que tendem a ter presença muito tênue (menor que 25\% - IF [Instituto de Física] e IQ [Instituto de Química]) as mulheres são tão produtivas quanto os homens, ou mais produtivas que eles, e naquelas em que comparecem de maneira mais marcante (acima de 30\% - IB [Instituto de Biologia] e IFCH [Instituto de Filosofia e Ciências Humanas]), elas tendem a ser menos produtivas em comparação aos homens. Este resultado, que à primeira vista pode ser considerado por alguns como surpreendente, de fato não o é. De acordo com a literatura, nos contextos em que conseguem ter presença marcante, as mulheres passam a imprimir seu próprio modelo de sucesso e buscam não imitar os valores e estilo de trabalho masculinos, tentando conciliar produtividade no trabalho às suas vidas exteriores ao laboratório". (VELHO, LEON, 1998, p. 337-338) 
Outra pesquisa, concretizada por Jacqueline Leta e Grant Lewison (2003) analisou a produção científica no Brasil nos campos da Oceanografia, Imunologia e Astronomia e constatou que a produtividade das cientistas é proporcional à presença delas nestas áreas. Assim sendo, refutou-se, mais uma vez, a hipótese de que a distribuição desigual entre homens e mulheres de cargos acadêmicos e bolsas de pesquisa se dê pela produção acadêmica inferior destas últimas.

Não obstante, faz-se necessário que muitas outras pesquisas sejam realizadas para que possamos compreender toda a complexidade do processo de exclusão das mulheres no meio acadêmico-científico, sobretudo no que concerne a concessão de bolsas e prêmios e, também, porquê demoram proporcionalmente mais do que os homens para ascenderem na hierarquia acadêmica. $\mathrm{O}$ que se pode afirmar, com segurança, é que existe um processo de marginalização das mulheres que é

[...] parte do fenômeno denominado de "teto de vidro", a existência de barreiras ao acesso a níveis de maior hierarquia e prestígio compromete, geralmente, as mulheres na construção da sua carreira na ciência. Portanto, mesmo que atualmente a participação das mulheres na ciência seja equitativa do ponto de vista numérico, a hierarquia acadêmica vai estar ocupada, sobretudo, por homens, independentemente da área do conhecimento. (SILVA; RIBEIRO, 2014, p. 450)

Além desta discriminação vertical, existe também o processo de discriminação horizontal, o qual se observa pelo maior número de cientistas mulheres em áreas menos prestigiadas e piores remuneradas. Pode-se deduzir que as mulheres têm maior acesso a estas áreas precisamente porquê são menos prestigiadas e/ou que tais áreas, quando passaram a ter maior predominância de mulheres, tornaram-se, impreterivelmente, menos valorizadas - verbi gratia, a carreira do magistério. Ainda que este seja um ponto fulcral para discussão, é evidente que a sua complexidade vai muito além do que se pretende ponderar nestas páginas. Contudo, notório é o fato de as escolhas profissionais que homens e mulheres realizam estão permeadas por concepções de mundo que são profundamente marcadas por estereótipos de gênero e sexualidade. Por esta razão, atualmente se denuncia que o pequeno envolvimento de mulheres em carreiras como a Física e a das Engenharias envolve um processo de socialização que afirma cotidianamente que elas não são hábeis para lidar com números e cálculos, o que engendra nas meninas um distanciamento das áreas das Ciências Exatas em torno da sétima série do ensino fundamental (VELHO; LEON, 1998, p. 341).

Assim, as barreiras impostas às mulheres, internalizadas ou externas, não se referem apenas às dificuldades de "subir" na carreira. O chamado teto de vidro é o resultado e a consequência de muitos e disseminados obstáculos. Preferi, portanto, a metáfora 


\begin{abstract}
"labirinto de cristal" para demonstrar as dificuldades de se estar no feminino e, simultaneamente, transitar no mundo das ciências. Não se trata, portanto, apenas de ascender na carreira científica, mas de atuar neste meio. O "labirinto de cristal" destaca barreiras a todo o momento encontradas pelas cientistas desde a entrada neste mundo, barreiras também invisíveis por não se tratar de barreiras formais, mas nem por isso menos concretas e contundentes. (LIMA, 2008, p. 120)
\end{abstract}

Podemos concluir, portanto, que muitas foram e continuam sendo as barreiras concretas e/ou simbólicas que as mulheres enfrentaram/afrontam no que concerne a sua real inclusão na esfera da Ciência. As discriminações de gênero são inúmeras e não se limitam às professoras-pesquisadoras em suas carreiras acadêmico-científicas, fato cada vez mais evidente com as conhecidas e popularizadas denúncias que estudantes de centros educacionais e universidades públicas e privadas de todo o país vêm realizando sistematicamente.

\title{
3. Atos de fala dos sujeitos mulheres historicamente emudecidas: denúncias sobre discriminação sexista nos Cursos de Direito
}

"A educação dos sujeitos coloniais complementa sua produção dentro da lei” (SPIVAK, 2010, p. 51)

Talvez uma das principais características das lutas feministas no início do século XXI seja a denúncia e a publicização de casos de preconceito, discriminação e/ou violências sexistas. Para o movimento feminista é antiga a compreensão de que o "privado é público" (EISENSTEIN, 1981, p. 188), mas com o desenvolvimento das novas tecnologias da informação e o acesso cada vez mais amplo a internet e as redes sociais, este caráter de publicização ganhou características particulares. E, mesmo quando se utilizam estratégias antigas de mobilização, elas atualmente podem ser resignificadas e divulgadas de modo muito mais expressivo por meio da internet. Um notório exemplo do que estamos argumentando, diz respeito ao movimento de estudantes de cursos de graduação que, através de cartazes fixados nas paredes dos corredores de distintas universidades brasileiras, trouxe a público as frases machistas, racistas, homofóbicas e classistas ditas pelo corpo docente de tais instituições de ensino.

No que segue, comentaremos o movimento de denúncias que ocorreu nas Faculdades de Direito da Universidade Federal de Santa Catarina (UFSC) e da Universidade Federal do Rio Grande (FURG). Ambas denúncias tiveram grande visibilidade no Facebook, oportunizando, desta forma, uma ampla divulgação pela rede social. Abaixo, alguns exemplos dessas denúncias realizadas entre os anos de 2015 e 2016: 


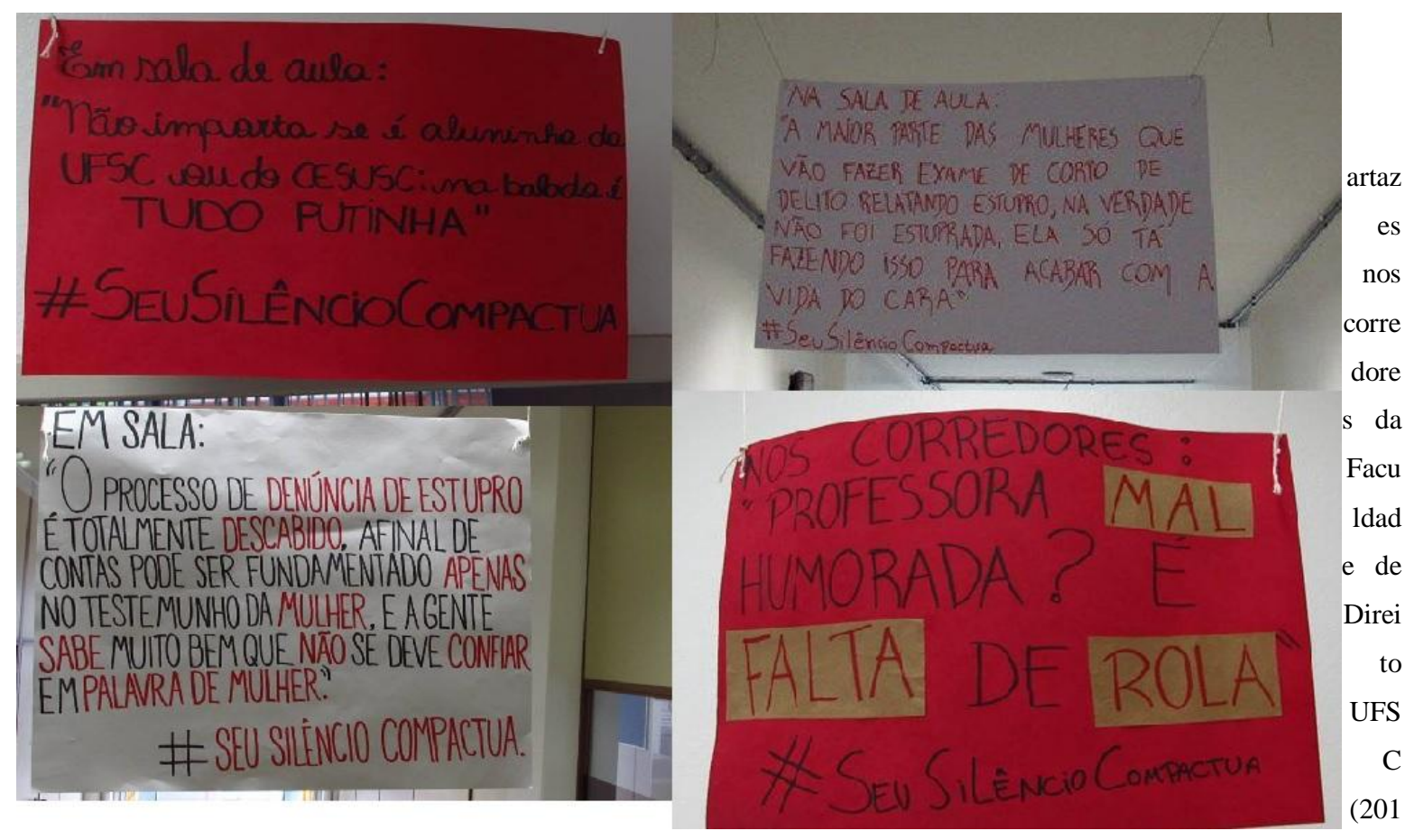

5)

H meuprofessormachista "Mulher é um bicho caro, mas entretém a gente."
\#MEUPROFESSORMACHISTA "Até o ano passado a aent bodia matar mulher, ma com a Laei do feminicidi $\cdots$ 
Cartazes nos corredores da Faculdade de Direito da FURG (2016)

Tais cartazes, espalhados nas sedes dos respectivos Cursos de Direito, demonstraram o que alunas e graduadas em Direito no Brasil conhecem muito bem: frases sexistas e misóginas - tais como a que consta no início desse artigo - e que são parte da formação cotidiana daquelas que desejam tornar-se bacharéis em Direito. É possível perceber, também, que os discursos machistas atacam não apenas as alunas, como também as professoras. Caberia, dado o conteúdo dos textos, uma reflexão sobre o ambiente educacional e profissional que permeia o meio acadêmico-científico brasileiro e, em especial, os cursos de Direito. Estas frases - uma pequena amostra dentre muitas outras escutadas em salas de aulas e transcritas nos cartazes pelas(os) estudantes - acabam somente corroborando os estereótipos de gênero transmutados, neste caso, para o discurso do Direito e das relações sociais acadêmicas.

Faz-se, portanto, fundamental compreender o que significa gênero. Conceito que decorre das demandas apresentadas pelo movimento feminista, quando das teorizações sobre as desigualdades entre homens e mulheres. Desde a perspectiva de gênero as diferenças entre homens e mulheres não se baseiam no sexo, afastando-se, assim, toda e quaisquer concepções naturalizantes e biologizantes, mas sim são fruto dos constructos socioculturais. Perspectiva teórica especialmente relevante e que busca rechaçar a legitimação de padrões e regras sociais a partir das diferenças biológicas e que historicamente atribuíram às mulheres um papel inexistente e/ou secundário na vida pública, mas obrigatório na esfera privada e dos cuidados e com as consequentes restrições no acesso à direitos. Portanto, o conceito de gênero ao mesmo tempo em que expõe as assimetrias e hierarquias nas relações entre mulheres e homens, torna visível a impossibilidade de compreender a amplitude dos papéis atribuídos aos sexos e seus simbolismos sem um estudo que seja relacional (PEDRO, 2007, p. 288-289).

A historiadora estadunidense Joan Scott esclarece que o elemento essencial de sua definição de gênero “[...] baseia-se na conexão integral entre duas proposições: o gênero é um elemento constitutivo de relações sociais baseado nas diferenças percebidas entre os sexos, e o gênero é uma forma primeira de significar as relações de poder” (SCOTT, 1995, p. 81). Logo, gênero se apresenta como um primeiro modo de dar significado para as relações de poder não sendo, portanto, coerente pensar nas diferenças entre homens e mulheres como algo atemporal e universal. A autora provoca uma reflexão sobre os modos como são socialmente 
interpretadas as diferenças biológicas, pois, segundo ela, são estas interpretações e construções sociais o elemento chave para compreender o gênero. Gênero é, portanto, o modo como se percebem tais diferenças em uma dada sociedade ${ }^{23}$ e é também

[...] igualmente utilizado para designar as relações sociais entre os sexos. O seu uso rejeita explicitamente as justificativas biológicas, como aquelas que encontram um denominador comum para várias formas de subordinação no fato de que as mulheres têm filhos e que os homens têm uma força muscular superior. O gênero se torna, aliás, uma maneira de indicar as "construções sociais" - a criação inteiramente social das idéias sobre os papéis próprios aos homens e às mulheres. É uma maneira de se referir às origens exclusivamente sociais das identidades subjetivas dos homens e das mulheres. O gênero é, segundo essa definição, uma categoria social imposta sobre um corpo sexuado. [...] O uso do "gênero" coloca a ênfase sobre todo um sistema de relações que pode incluir o sexo, mas que não é diretamente determinado pelo sexo nem determina diretamente a sexualidade. (SCOTT, 1995, p. 78 , grifos da autora)

Os estereótipos de gênero são arquétipos que se constroem a partir do que se compreende, em uma dada sociedade, como sendo característica de um determinado gênero. No caso da sociedade ocidental, onde predomina uma visão binária e dicotômica, se atribuem as pessoas características tidas como femininas ou masculinas. Esta atribuição não é, a priori, prejudicial para os indivíduos ou à sociedade, porém, considerando que linguística e majoritariamente se considera positivo tudo que é atribuído ao gênero masculino, é inegável que esta identificação hierarquizada tende a gerar uma forte discriminação por atribuir às mulheres características menos valorizadas e, até mesmo, indesejáveis, em especial quando se trata da vida na esfera pública e do trabalho.

Este processo de inferiorização das mulheres pode ocorrer de distintos modos. Um deles é, sem dúvida, a suposição de que a fala da mulher não deve ser tomada em consideração, não é digna de ser ouvida. As frases reproduzidas nos cartazes em comento, deslegitimam as mulheres, atribuindo-lhes um lugar desqualificado no mundo, inclusive na

23 As pesquisas sobre gênero ocorreram e todavia são realizadas em distintas áreas do conhecimento e a partir de múltiplas perspectivas teóricas. Não é o propósito desse texto realizar um panorama acerca do conceito. Contudo, vale destacar que diversos estudos a partir da década de 1980, produziram sérios debates sobre igualdade e diferenças e questionaram fortemente a clássica distinção entre gênero e sexo, enquanto categorias de ordem distintas - uma da cultura e a outra da natureza - por serem consideradas estanques e admitirem a existência de apenas dois gêneros possíveis e opostos: o feminino e o masculino. Tais questionamentos à visão mais clássica de gênero complexifica largamente as discussões sobre as diferenças entre mulheres e homens. Para começar, coloca em xeque a própria distinção entre sexo e gênero, na medida em que o modo como os seres humanos definem e separam o que é biológico e o que é cultural (ou, a distinção entre cultura e natureza) também é um processo que se constrói a partir de relações sociais de poder. Logo, "a 'diferença sexual' foi estabelecida não somente como um fato natural, mas também como uma base ontológica para diferenciação política e social." (SCOTT, 2005, p. 21). 
esfera jurídica. Quando o professor afirma que "a gente sabe muito bem que não se deve confiar em palavra de mulher", ele está reforçando uma violência histórica de silenciamento e de deslegitimação da fala das mulheres, reforçando, portanto, o local da mulher enquanto "sujeito historicamente emudecido" como definiu a pós-colonialista indiana Gayatri Chakravorty Spivak (apud BAHRI, 2013, p.659). O ato de fala - ou seja, o fato de que as mulheres têm o poder de denunciar uma violência sofrida - não é suficiente em si mesmo, pois “a comunicação abrange não apenas o ato da 'fala', como também o da recepção, da audição e da interpretação." (BAHRI, 2013, p. 660, grifos da autora). Desse modo, o valor atribuído tanto ao presumido natural comportamento demeritório das mulheres e suas usuais falas como sendo sempre e necessariamente inferiores e menos legítimas que o discurso masculino é uma forma de violência em si mesma e que, imperiosamente, contribui para a perpetuação em todos os âmbitos públicos e privados de outras formas de violências (dentre elas, a física, a psicoemocional, a moral e a sexual).

\section{Conclusão}

Analisar o sexismo e a violência simbólica que perpassa o mundo acadêmico na atualidade é reconhecer as limitações do processo de inclusão das mulheres enquanto destinatárias e agentes do saber formal e do fazer científico. O inegável status de importância da Ciência a partir do contexto moderno-colonial é coerente com a constante exclusão das mulheres, das pessoas negras e também pobres destes espaços de saber-poder, originados e consolidados como espaços masculinos, brancos e elitistas. Os avanços formais no direito de acessar a tais espaços são extremamente importantes. Apesar disso, neste segundo decênio do século XXI é mais do que urgente que o acesso formal, finalmente, resulte em condições materiais de igualdade.

Partindo destes entendimentos, a presente pesquisa traçou um sistemático panorama histórico do acesso das mulheres à educação formal e destacou como, gradativamente, as lutas feministas resultaram em regulamentações que, na atualidade, não permitem qualquer tipo de discriminação sexista no acesso à graduação e pós-graduação. Contudo, foi possível identificar que os postos de chefia e as bolsas de pesquisa e produtividade ainda são distribuídas de forma proporcionalmente desigual, o que torna notório o teto de vidro invisivelmente existente e persiste na academia brasileira. Ao mesmo tempo, o labirinto de cristal que norteia o espaço acadêmico-científico reforça as barreiras não apenas verticais, 
mas também horizontais, na medida em que certas áreas do conhecimento são majoritariamente dominadas por homens, de modo que se perpetuam os mitos e estereótipos de gênero no momento de acesso e permanência no ensino superior. Por essa razão, as mulheres são inseridas e aceitas em carreiras que envolvem a ideia de "cuidado" e afastadas de áreas que denotam raciocínio técnico e matemático - o que resulta em desvalorização da primeira em oposição à valorização econômica e social da segunda.

Nesse cenário não é surpreendente, portanto, que os violentos discursos sexistas e misóginos trazidos a colação neste paper - e que nada mais são do que uma constante em todo território nacional -, perpassem também os espaços acadêmico-científicos do Direito, área do conhecimento heteronormatizante e sexista desde suas origens.

\section{Referências}

ALMEIDA, Jane Soares de. Mulheres na escola: Algumas reflexões sobre o magistério feminino. Cadernos de Pesquisa, Universidade de São Paulo, n.96, fev. 1996, São Paulo, p. 71-78.

Mulher e educação: a paixão pelo possível. São Paulo: UNESP, 1998.

BAHRI, Deepika. Feminismo e/no pós-colonialismo. Estudos Feministas, v.21, n.2, maiago, 2013, Florianópolis, p. 659-688.

BELTRÃO, Kaizô Iwakami. ALVES, José Eustáquio Diniz. A Reversão do Hiato de Gênero na Educação Brasileira no Século XX. In: Cadernos de Pesquisa, Fundação Carlos Chagas, v.39, n.136, jan/abr, 2009, São Paulo, p. 125-156

BOURDIEU, Pierre. A dominação masculina. Tradução Maria Helena Kühner. Rio de Janeiro: Bertrand Brasil, 1999.

CASTRO-GÓMEZ, Santiago. La Poscolonialidad Explicada a los Niños. Popayán: Editora Universidad del Cauca, 2005.

DUSSEL, Enrique. Europa, Modernidade de Eurocentrismo. In: A Colonialidade do Saber Eurocentrismo e Ciências Sociais Perspectivas Latino-Americanas. Edgardo Lander (org). Buenos Aires: Consejo Latinoamericano de Ciencias Sociales - CLACSO, 2005. p. 55-70.

. Eurocentrismo y Modernidad (Introducción a las Lecturas de Frankfurt).

Disponível

em:

http://enriquedussel.com/DVD\%20Obras\%20Enrique\%20Dussel/Textos/c/243.1993/articulo. pdf. Acesso em 11 de março de 2013. 
EISENSTEIN, Zillah $\mathrm{R}$. The radical future of liberalism feminism. 2.ed. Boston: Notheaastern University Press, 1981.

INEP: Censo da Educação Superior 2016. Brasília: Inep, 2016.

IPEA. Mulheres e trabalho: breve análise do período 2004-2014. Nota Técnica n.24. Brasília: IPEA, 2016.

LETA, Jacqueline. As mulheres na ciência brasileira: crescimento, contrastes e um perfil de sucesso. Revista Estudos Avançados, Universidade de São Paulo (USP), v.49, n.17, 2003, São Paulo, p. 271-284.

LETA, Jacqueline; LEWISON. Grant. The contribution of women in Brazilian science: A case study in astronomy, immunology and oceanography. Scientometrics, v.57, n.3, 2003, p. 339-353

LIMA, Betina Stefanello. Teto de vidro ou labirinto de cristal?: as margens femininas das ciências. Dissertação de Mestrado apresentada ao Programa de Pós- Graduação em História da Universidade de Brasília. Orientadora: Prof ${ }^{a}$. Dr ${ }^{\mathrm{a}}$. Rita Laura Segato. Brasília: Universidade de Brasília, 2008.

LOURO, G. Gênero e Magistério: Identidade, História, Representação. In: CATANI, Delmira, et. all. (org.). Docência, memória e gênero: estudos sobre formação. São Paulo: Escrituras Editora, 1997.

PEDRO, Joana Maria. Os feminismos e os muros de 1968, no Cone Sul. Clio - Série de Pesquisa Histórica, v.1, n.26, 2008, São Paulo, p. 59-82

Narrativas fundadoras do feminismo: poderes e conflitos (1970-1978). Revista Brasileira de História, v.26, n.52, 2006, São Paulo, p. 249-272.

Traduzindo o debate: o uso da categoria gênero na pesquisa histórica. Revista Brasileira de História, v. 24, n.1, 2005, São Paulo, p. 77-98

ROUSSEAU, Jean-Jacques. Emílio ou Da Educação. Tradução de Roberto Leal Ferreira. Martins Fontes. 2.ed. São Paulo: Martins Fontes, 1999.

SPIVAK, Gayatri Chakravorty. Pode o subalterno falar?. Tradução de Sandra Regina Almeida, Marcos Feitosa e André Feitosa. Belo Horizonte: Universidade Federal de Minas Gerais, 2010.

STOLZ, Sheila. A odisseia dos direitos fundamentais: sobre a igualdade entre mulheres e homens e a conciliação da vida laboral e familiar no Direito espanhol. Tese Doutoral apresentada ao Programa Pós-Graduação em Direito da Faculdade de Direito da Pontifícia 
Universidade Católica do Rio Grande do Sul. Orientador: Prof. Dr. Draiton Gonzaga de Souza. Porto Alegre: Pontifícia Universidade Católica do Rio Grande do Sul, 2015.

STOLZ, Sheila; GUSMÃO, Carolina Flores. A influência da Frente Parlamentar da Agropecuária (FPA) na legislação e na formulação de políticas públicas direcionadas às pessoas que trabalham no meio rural. NOMOS, Revista do Programa de Pós-Graduação em Direito da Universidade Federal do Ceará (UFC), v. 37, n. 2, jul./dez., 2017, Fortaleza, p. 299-330.

SANTOS, Boaventura de Sousa. A Crítica da Razão Indolente: Contra o Desperdício da Experiência. Para um novo senso comum: a ciência, o direito e a política na transição paradigmática - Volume 1. 7. ed. São Paulo: Cortez Editora, 2009.

SCOTT, Joan W. Gênero: uma categoria útil para análise histórica. Educação \& Realidade, v.20, n.2, jul./dez, 1995, Porto Alegre, p. 71-99

SILVA, Fabiane Ferreira da. RIBEIRO, Paula Regina Costa. Trajetória de mulheres na ciência: "ser cientista" e "ser mulher". Ciência e Educação, v.20, n.2, 2014, Bauru, p. 449466.

VALCÁRCEL, Amélia. La Política de las mujeres. Madrid: Cátedra, 1997. 